\title{
A Study of Sound Environments to Effectively Facilitate User's Learning and Research in College Libraries
}

\author{
Hatsue WADA ${ }^{\mathrm{a}^{*}}$, Yukio MORI ${ }^{\mathrm{a}}$. \\ ${ }^{a}$ Salesian Polytechnic, 4-6-8 Oyamagaoka, Machida-City, Tokyo, 194-0215,Japan \\ *Corresponding Author: wada@salesio-sp.ac.jp
}

\begin{abstract}
In previous studies, genuinely silent sound environment was created using sound masking ${ }^{(1)}$ at the Polytechnic College library. This "place" where learning commons can occur without disruption to individual learning and reading is examine in this study ${ }^{(2)}$. In the research, one user commented "I can concentrate better when there is music that I like being played rather than being in a completely silent environment". From these results, we suggest that the possibilities are as follows. First, control of the sound environment changes a library into a "place" to realize a variety of utilizations. Next, sound environment that is "comfortable" for users improves their concentration and eventually promotes educational and research effects in library utilization. In this study, we investigate recognition of the sound environment of libraries. The results, confirm the following trends regarding recognition of Background Music (BGM) in college libraries.

- BGM has the effect of enhancing concentration and relaxation for personal learning and reading.

- Music that is focused on melody and harmony is preferable as BGM, whereas music focused on vocals is dispreferred.

Based on these results, a method was identified to develop a sound environment for libraries.

In this paper, we describe the results of preliminary research regarding recognition of BGM in libraries. We then propose method of developing a sound environment that increases concentration of library users and effectively facilitates learning and research by not only changing a library into a "place" that realizes various purposes of use but by creating a sound environment where users feel "comfortable".
\end{abstract}

Keywords: sound environment, library, sound masking.

\section{Introduction}

In recent years, educational institutions equipped with learning commons aimed at effective learning have increased. At many educational institutions, libraries are used as a "place" to practice learning commons. At present, libraries designed with a view to implementing shared learning commons are scarce. Therefore, the coexistence of individual learning and reading in a quiet sound environment typical of a conventional library, and learning collaboratively, which assumes communication with others is difficult. The same issue exists at public libraries. Public libraries have been identified as a "place" in the local community where integration with community facilities is being sought. As a solution to these problems, at Musashino Place which is a public library, the sound environment in the building has been zoned by adopting "sound masking", it has implemented ambient noise measures by not creating extremely silent spaces ${ }^{(1)}$. Hence, by using sound masking, we created a genuinely silent "place" where learning commons can be undertaken without disruption to individual learning and document viewing. In the user's interviews, a comment made was "I can concentrate more when my favorite music is being played rather than in a completely silent environment". Moreover, at a symposium titled "Sound and Learning in a Library" held in 2015, it was reported that the distinction between sound which makes one feel "comfort" and sound which makes one feel "annoyance" differs according to each person, the situation, and their state of mind at the time, and that these factors should be taken into consideration, assuming that one understands general sound characteristics and the variety and frequency of sound sources occurring in a library. ${ }^{(3)}$ The symposium provided suggestions about controlling the sound environment in a library, not only by changing a library into a "place" with various uses but by creating a sound environment in which users feel "comfortable", and 
thus one in which effective learning and research can be had facilitated.

The purpose of this study is to develop a sound environment that facilitates effective learning and research for library users. Sound sources "comfortable" for users whether reading, learning individually, or engaging in active learning are clarified through a preliminary investigation at the Polytechnic College library. However, the sound sources are assumed to depend on individual characteristics, so an interview survey will also be conducted to examine the relationship between individual tastes in music, age, and gender, which may have an impact on psychological changes. Based on the results, sound environments are will be created experimentally created and set up; the promotion of educational and research effects on users will then be examined in accord with the results of a questionnaire survey to determine usefulness.

In this paper, we discuss the results of a preliminary investigation to develop a sound environment to effectively facilitate learning and research, and propose the development of a method of establishing sound environments based on the results.

\section{Preliminary investigation}

The methodology of the preliminary investigation was as follows.

(a) Purpose

The purpose of this investigation was to understand the trends in the following items when developing a sound environment.

(1) Awareness of preferred sound environment when studying alone or in a group.

(2) Awareness of effects of BGM by user's purpose in the library.

(3) Awareness of preferred BGM in the library.

(b) Participants

The subjects were students who used the reading space in the Polytechnic College library. A total of 22 valid responses were received (five 1 st grade students, four 2 nd grade students, six 3rd grade students, six 4th grade students, and one 5th grade student).

(c) Investigation period

May 8, 11-12, 2017

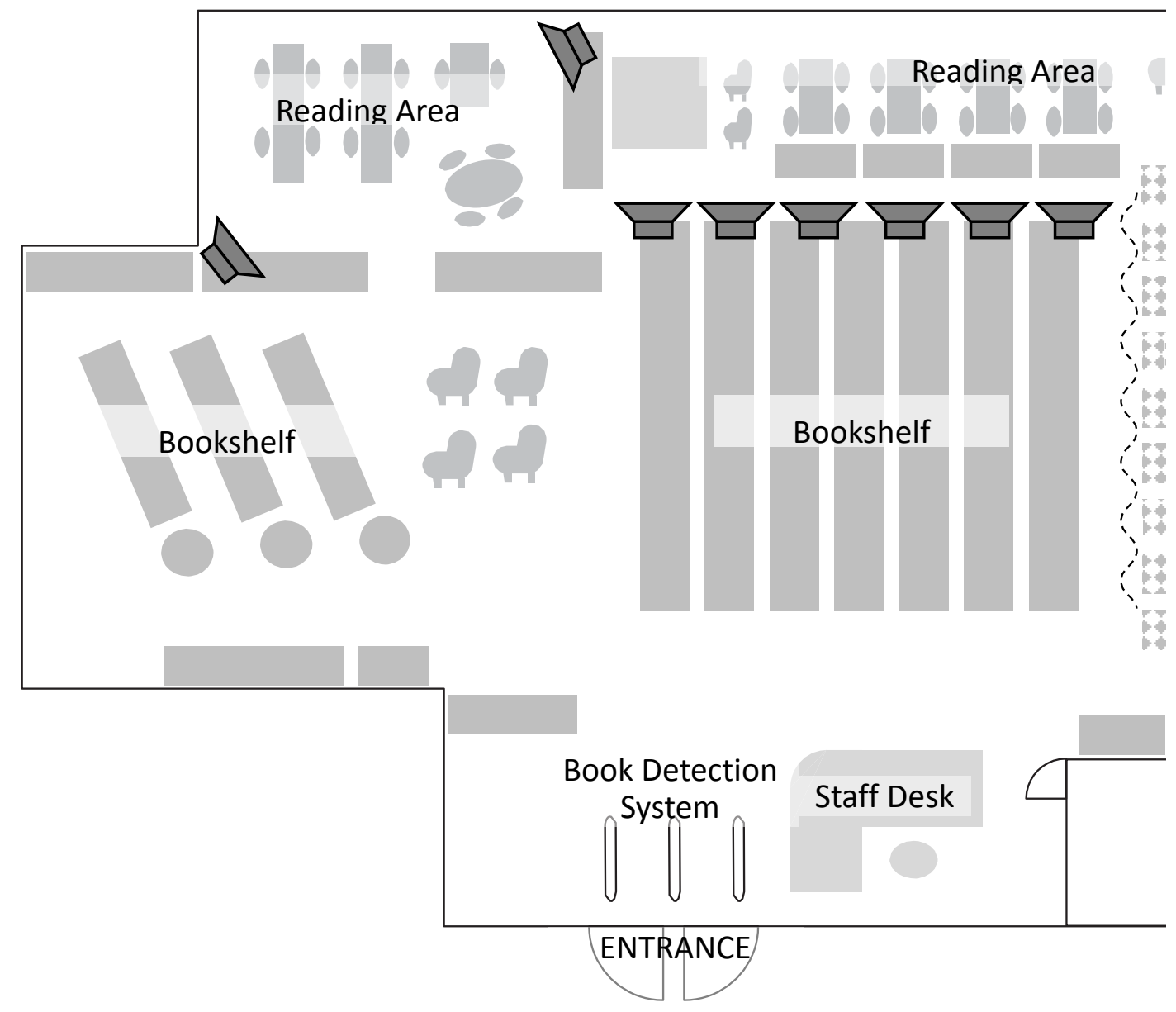

Fig. 1 The layout of the library. 


\section{(d) Investigation method}

We set up speakers around the reading space in the library and played environmental BGM music with $1 / f$ fluctuation, which exerts an effect on the autonomic nervous system, according to previous studies. We created a sound environment in which the volume of the music was at a slightly higher level than the background noise of the library.

Next, a questionnaire concerning the three items above was administered to users of the reading area. We show the layout of the library in Fig. 1.

\section{Preliminary investigation results}

\subsection{Desirable sound environment for individual or group learning}

We show the preferred sound environment for individual learning and for group learning, in Table 1 and 2, respectively. These results revealed a clear trend in which

Table 1. Preferred sound environment for individual learning $(n=22)$

\begin{tabular}{l|c|c|c}
\hline & agree & disagree & not sure \\
\hline \hline $\begin{array}{l}\text { It is easier to learn when } \\
\text { BGM is playing }\end{array}$ & 14 & 1 & 7 \\
\hline $\begin{array}{l}\text { It is easier to learn in a } \\
\text { quiet place }\end{array}$ & 7 & 8 & 7 \\
\hline $\begin{array}{l}\text { It is easier to learn in a } \\
\text { place with people } \\
\text { (e.g., library, cafe) }\end{array}$ & 8 & 6 & 8 \\
\hline
\end{tabular}

Table 2. Preferred sound environment for group learning $(n=22)$

\begin{tabular}{l|c|c|c}
\hline & agree & disagree & not sure \\
\hline \hline $\begin{array}{l}\text { It is easier to learn when } \\
\text { BGM is playing }\end{array}$ & 12 & 4 & 6 \\
\hline $\begin{array}{l}\text { It is easier to learn in a } \\
\text { quiet place }\end{array}$ & 4 & 9 & 9 \\
\hline $\begin{array}{l}\text { It is easier to learn in a } \\
\text { place with people } \\
\text { (e.g., library, cafe) }\end{array}$ & 7 & 4 & 11 \\
\hline
\end{tabular}

Table 3. Activities for which BGM was most effective examined by user's purpose in library (multiple answers)

\begin{tabular}{l|c|c|c}
\hline Purpose of use & $\begin{array}{c}\text { Individual } \\
\text { learning } \\
(n=11)\end{array}$ & Reading & $\begin{array}{c}\text { Group } \\
\text { reading } \\
(n=5)\end{array}$ \\
\hline Concentrating & 5 & 3 & 1 \\
\hline Relaxing & 8 & 4 & 3 \\
\hline
\end{tabular}

users report that it is easier to learn if BGM is playing in the case of both individual learning and group learning. Particularly in the case of individual learning, a larger number of individuals responded that it was easier to study when BGM was playing. It can be surmised that BGM in libraries has the effect of enhancing concentration and relaxation for individual reading and learning.

\subsection{The effects of BGM by use of library}

The responses concerning the two activities for which BGM was reported to be especially useful are shown for each use in Table 3 .

The activities for which BGM was most useful were concentrating and relaxing. The most common responses for concerning user's purpose in the library were "individual learning" and "reading". Additionally, of the users who identified "concentrating" and "relaxing", four were there for individual learning while three were there to read. Based on these results, it can be assumed that BGM was effective for individual learning rather than group learning; the primary effects seem to be "promotion of ability to concentrate" and "relaxation". We also confirmed that BGM did not have a negative influence to reading, as a previous study demonstrated ${ }^{(4)}$.

\subsection{Awareness of preferred BGM in the library}

We show the music that is preferred as BGM, in Table 4. These results revealed that the preferred library BGM emphasizes melody and harmony, and has a simple rhythm. Conversely, it was found that music with a fast tempo and emphasis on vocals is dispreferred. We confirmed the findings a previous study has demonstrated ${ }^{(5)}$, namely, that music containing lyrics is not suitable for BGM. 
Table 4. Concerning music that is preferred in the library BGM $(n=21)$

\begin{tabular}{l|c|c|c}
\hline & agree & disagree & not sure \\
\hline \hline $\begin{array}{l}\text { sound with emphasis } \\
\text { on melody }\end{array}$ & 11 & 2 & 8 \\
\hline $\begin{array}{l}\text { sound with emphasis } \\
\text { on harmony }\end{array}$ & 8 & 3 & 10 \\
\hline $\begin{array}{l}\text { sound with simple } \\
\text { rhythm }\end{array}$ & 9 & 3 & 9 \\
\hline $\begin{array}{l}\text { sound with emphasis } \\
\text { on fast tempo }\end{array}$ & 4 & 6 & 11 \\
\hline
\end{tabular}

\section{Development method of sound environment}

In studying the sound environment, through listening experiments, at the Polytechnic College library, we identified the sound source that makes users feel "comfortable" with each purpose; reading, individual learning, and active learning.

However, the effects of the sound source, will presumably vary greatly according to the characteristics of the individual and the circumstances, therefore the next step is to conduct interviews and assess individual musical tastes that influence psychological changes, and verify the relationship between age and sex. The details are as follows.

(1) Multiple sound sources (including the natural sound environment) of different musical genres will be prepared and the sound sources with which users feel "comfortable" will be extracted. Specifically, the subjectivity of the test subject is converted into numerical form using VAS (Visual Analog Scale) and simultaneously, the active physical state of the test subject is quantified using heart rate variability analysis. The sound source is then determined based on the results of a correlation analysis.

(2) Next, information regarding individual characteristics of the test subjects, including musical tastes, age, and gender are obtained from the interviews. Users who feel the sound source is "comfortable" are categorized.

(3) Based on the results of (1) and (2), a prototype of the actual sound environment is created and set up. However, if many sound environments exist because of user categorization and differences in usage, then the set up will be based on the most appropriate matrix of user categorization and library usage. Subsequent questionnaire surveys will be undertaken with a wide range of library users, the results analyzed, and further usefulness considered.

Informed consent from the test participants regarding their cooperation in the experiment to measure bio-signals and their subjective evaluation will be obtained.

\section{Conclusion}

In this paper, we described the results of a preliminary investigation to develop a sound environment to facilitate effective learning and research, and the method for developing a sound environment based on the results.

Such a sound environment can also be applied to other educational institutions' libraries and public libraries; given the need to diversify the role of libraries, this study is significant as a means of facilitating that development.

\section{Acknowledgment}

This work was supported by JSPS KAKENHI Grant Number $17 \mathrm{H} 00079$.

\section{References}

(1) Nobuyuki Hirayanagi, Toru Ajisaka, Makiko Masudome: "Influence of sounds environment by user in composited library", Summaries of technical papers of the annual meeting of the Architectural Institute of Japan, Vol. 53, pp. 101-104, 2014 (in Japanese).

(2) Hatsue Wada: "Trial of learning commons which supports active learning in creative education, https://kaken.nii.ac.jp/ja/grant/KAKENHI-PROJECT-1 $\underline{6 \mathrm{H} 00087 /}$ as of June 7, 2017 (in Japanese).

(3) Symposium-Report: "Sound and learning in a library", Current Awareness E, No. 279, 2015 (in Japanese).

(4) Cecil M. Freeburne, Murray S. Fleischer: "The effect of music distraction upon reading rate and comprehension", Journal of Educational Psychology, Vol. 43, No. 2, pp. 101-109, 1952.

(5) Tadasuke Monma, Kaoru Honda: "Examination of the impact of verbal information contained in music on reading task", The Japanese Journal of Ergonomics, Vol. 45, No. 3, pp. 170-172, 2009 (in Japanese). 